\title{
Are Nigerian oral health workers overlooking opportunities to promote interventions for tobacco smoking cessation?
}

\author{
Afolabi Oyapero ${ }^{1}$, Olubukola Olamide Olatosi ${ }^{2}$, Olufemi Olagundoye ${ }^{1}$
}

\author{
AFFILIATION \\ 1 Department of Preventive Dentistry, Faculty of Dentistry, Lagos State \\ University College of Medicine, Lagos, Nigeria \\ 2 Department of Child Dental Health, Faculty of Dental Sciences, College \\ of Medicine University of Lagos, Nigeria
}

CORRESPONDENCE TO

Afolabi Oyapero. Department of Preventive Dentistry, Faculty of Dentistry,
Lagos State University College of Medicine, 1-5 Oba Akinjobi Way, G.R.A., Ikeja P.M.B. 21266, Lagos, Nigeria. E-mail: fola_ba@yahoo.com

KEYWORDS

tobacco, smoking, dentists, cessation

Received: 29 July 2020, Revised: 22 December 2020,

Accepted: 9 January 2021

https://doi.org/10.18332/popmed/132292

Popul. Med. 2021;3(February):6

RESULTS A total of 15786 new patients, mean age $49.3 \pm 12.8$ years, were reviewed. Only 4104 (26\%) of the patients had their tobacco use history documented; of these, 656 (16\%) indicated past or current tobacco use; only 120 $(18.3 \%)$ of these were referred for cessation counseling in the preventive dentistry unit. Males $(n=611 ; 93.1 \%)$ had a higher proportion of past or present tobacco use. Patients presenting with oral ulcers $(\mathrm{OR}=1.94)$ and jaw tumors $(\mathrm{OR}=2.45)$ were significantly more likely to be screened for tobacco use.

CONCLUSIONS Less than $0.01 \%$ of new patients were provided with tobacco use cessation advice, and opportunities for screening were essentially unexploited implying an urgent need to incorporate tobacco cessation interventions as part of standard clerking sheets for patients.

\section{INTRODUCTION}

Tobacco consumption occurs in many forms such as cigarettes, pipes, cigars, cigarillos, bidis, kreteks, smokeless tobacco (chew, snuff, and dissolvable strips, sticks, or lozenges), and through a hookah or waterpipe. The most common and referenced version of tobacco use is smoking. According to the U.S. Food and Drug Administration (FDA), the categories of smoked tobacco products are cigars, hookah, pipe tobacco, roll-your-own tobacco, electronic nicotine delivery systems and cigarettes. A cigarette is a thin cylinder of finely cut tobacco rolled in paper for smoking with chemical additives and a filter. There are 93 known harmful and potentially harmful chemicals in cigarettes including nicotine, cadmium, lead, acetaldehyde, ammonia, and benzene, and more than 7000 chemicals in cigarette smoke itself ${ }^{1}$. Close to $80 \%$ of the world's 1 billion smokers live in low- to middle-income countries, like Nigeria ${ }^{2}$. Due to poor regulatory framework and weak governing systems, easy distribution of tobacco products, the initiation and maintenence of tobacco use is widely prevalent in Nigeria. Currently, about 1 in every 5 Nigerians smokes ${ }^{3}$, with high prevalence of consumption, as high as $50 \%$ among highrisk occupations like truck drivers ${ }^{4}$. Over 20 billion sticks of cigarettes are consumed annually in the country ${ }^{3}$.

The World Health Organization (WHO) estimates that tobacco kills nearly 7 million people annually while 100 million tobacco related deaths were recorded over the course of the 20th century ${ }^{5}$. Tobacco is the leading preventable cause of mortality globally, contributing to cancer, cardiac disease, stroke, chronic lung diseases and other non-communicable 
diseases ${ }^{6}$. Furthermore, the consumption of tobacco products also has a negative impact on oral health; tobacco smoking is a significant etiological factor in periodontal diseases, deficits in postoperative oral healing and recovery, and plays a role in the failure of dental implants ${ }^{7}$. These diseases not only affect disability adjusted life years (DALYs), but also lead to a significant economic burden on societies ${ }^{8,9}$.

One of the six measures developed to advance tobacco control is to 'offer help to quit tobacco use'10 in the WHO Framework Convention for Tobacco Control, which is ratified by 177 countries worldwide. Substantial evidence shows that smoking cessation reduces mortality from tobaccorelated diseases and improves health ${ }^{11}$. However, smoking is a powerful addiction and despite numerous quit attempts, many individuals who smoke frequently fail to stop smoking ${ }^{12}$. Smoking cessation programs are therefore necessary to provide the support required for smokers to quit ${ }^{13}$. An analysis of 17 trials investigating physicians' advice as an intervention concluded that even brief advice was effective in increasing the odds ratio for quitting smoking (1.74) ${ }^{14}$. National health organizations and organized dentistry have long advocated for practitioners to take a more active role in tobacco interventions with their patients ${ }^{13,15}$.

Carr and Ebbert ${ }^{16}$ have reported that abstinence rates may increase among tobacco users as a result of behavioral interventions with an oral examination component provided by dentists and their auxiliaries in clinics or community settings. Dental healthcare providers are a great resource to aid in tobacco cessation. The patient-dentist relationship is unique; the dentist has the opportunity to meet his/her patient over many visits, which provides the opportunity to initiate and reinforce tobacco cessation practices. Dentists are experienced and knowledgeable in diagnosing oral disease ${ }^{4}$, particularly the adverse oral health effects of tobacco smoking, which on many occasions are present as potentially malignant or malignant lesions. Dentists can provide cessation assistance to their patients by identifying the oral signs of tobacco use, informing patients of these and assessing their willingness to quit smoking. They can also refer patients who desire to quit for smoking cessation services. It is estimated that about $50 \%$ of patients visit their dentist at least once a year ${ }^{17}$.

In many countries, dentistry may be a potential setting for several aspects of clinical public health interventions because of their regular recall system of patients, presenting opportunity for promoting life style changes. In a recent Nigerian study, about half of the patients visiting the teaching hospital attended the dental clinic, a very high proportion ${ }^{18}$. Thus, the dental office visit provides a unique opportunity for dental professionals to point out the detrimental effects of tobacco and to discuss and assist in quitting. Cessation assistance within the dental clinic can be defined as referring patients for cessation counseling in the preventive dentistry unit. Since dentists are strategically positioned to promote tobacco abstinence and cessation of tobacco use, we aimed to review patients' dental records in one of the busiest tertiary dental clinics in Nigeria to determine if tobacco use was documented and referral services for tobacco cessation were made.

\section{METHODS}

This retrospective and descriptive study utilized the dental records and case histories of patients (aged 12-80 years) seen at the oral diagnosis unit of the Lagos State University Teaching Hospital, Nigeria, over 2 years. The study was done at the dental center of the Lagos State University Teaching Hospital (LASUTH), which is the clinical division of Faculty of Dentistry, Lagos State University College of Medicine. Ethical approval for the study was obtained from the Health Research and Ethics Committee of the Lagos State University Teaching Hospital, Ikeja. The study was implemented in line with the Declarations of Helsinki and the confidentiality of all the participants was assured by the researchers. An official written request, which was approved, was also obtained from the medical records department of the Hospital. Written informed consent was not taken since the data were retrieved anonymously from the patients' records and confidentiality was guaranteed by omitting personal identifiers.

The inclusion criteria were male and female subjects presenting for the first time to the dental center. The exclusion criteria included case files with incomplete information with respect to age and gender and missing diagnosis or treatment plan.

The principal investigator and a second researcher were responsible for data collection using 40 randomly selected dental records of patients at the oral diagnosis unit of the dental center which were not included in the final analysis. Inter-examiner reliability for both examiners was 0.90 , whereas the intra-examiner reliability was 0.92 and 0.87 for the two examiners, respectively. The dental records of the patients were subsequently retrieved by the dental record officers after they obtained the written permission from the medical records department. The principal investigator used a proforma to record the date of birth, gender, the presenting complaint and diagnosis made by the attending dentist, documentation of tobacco use history and treatment plan, including referral of the patient to the Preventive Dentistry unit for smoking cessation. The chart review procedure was replicated by the other examiner and the records were compared for reproducibility and consistency. Other sociodemographic parameters such as socioeconomic status, religion, and occupation were not included during the assessment of the patients' dental records.

\section{Statistical analysis}

Data were entered and analyzed using the Statistical Package for the Social Sciences (SPSS) software, version 20 (IBM, Armonk, New York). Descriptive statistics were used to quantify variables such as age, gender, history of tobacco use and referral to the preventive dentistry cessation clinic. Descriptive statistics included the mean age, sex distribution, 
and smoking status of the survey respondents. Data were analyzed by $\chi^{2}$ tests, t-test, and linear regression analysis. The confidence and significant levels for statistical analysis were set at $95 \%$ and $5 \%(p \leq 0.05)$, respectively.

\section{RESULTS}

In this study, 15786 clinical records of patients who attended the oral diagnosis unit of the Dental Centre, LASUTH, from 2017-2018, were retrieved and reviewed. The mean age of the patients seen in 2 years was $49.3 \pm 12$. 8 years while the age range was $12-80$ years. The highest proportions of subjects were aged $26-35$ years $(n=4894 ; 31.0 \%)$, whereas the least number of subjects were aged $76-80$ years $(n=189 ; 1.2 \%)$. Overall, there were more females $(n=8319$; $52.7 \%)$ than males $(\mathrm{n}=7467 ; 47.3 \%)$. The age and gender distribution is presented in Table 1.

Table 2 shows the patient's reasons for their dental visit, from their records. The majority had toothache $(n=12913$; $81.8 \%$ ). Decayed teeth was the next most common reason $(n=931 ; 5.1 \%)$ indicated in the dental records, while routine preventive dental visit $(n=47 ; 0.3 \%)$ was the least prevalent reason documented.

Table 3 shows the tobacco use related history of the study subjects. Only 4104 (26\%) of the patients had their tobacco use history documented; of these, $656(16 \%)$ indicated past or current tobacco use; only 120 (18.3\%) of these were routinely offered cessation assistance. Males ( $n=611 ; 93.1 \%)$ had a higher proportion of past or present tobacco use.

Table 4 displays the odds ratio and confidence interval of a patient receiving screening for tobacco use based on their presenting complaint. Patients presenting with oral ulcers (OR=1.94; 95\% CI: $1.26-2.84$ ), jaw tumors (OR=2.45; 95\% CI:

Table 1. Sex and age distribution of study subjects seen at the oral diagnosis unit of the Lagos State University Teaching Hospital, Nigeria 2017-2018 ( $\mathrm{N}=15786)$

\begin{tabular}{l|c|c|}
\hline Characteristics & $\mathbf{n}$ & $\%$ \\
\hline Sex & & \\
\hline Male & 7467 & 47.3 \\
Female & 8319 & 52.7 \\
Total & 15786 & 100 \\
\hline Age group (years) & & \\
$12-25$ & 4782 & 30.3 \\
$26-35$ & 4894 & 31.0 \\
$36-45$ & 2462 & 15.6 \\
$46-55$ & 1499 & 9.5 \\
$56-65$ & 1152 & 7.3 \\
$66-75$ & 789 & 5.0 \\
$76-80$ & 189 & 1.2 \\
Total & 15786 & 100
\end{tabular}

1.67-4.38), periodontitis (OR=1.43; 95\% CI: $0.89-2.04)$ and mouth odor (OR=1.38; 95\% CI: $1.05-1.83$ ) were significantly more likely to be screened for tobacco use compared to those with other dental complaints.

Table 2. Patient's reasons for the dental visit to the oral diagnosis unit of the Lagos State University Teaching Hospital, Nigeria 2017-2018 ( $N=15786)$

\begin{tabular}{l|r|r|} 
Reason for visit & n & $\%$ \\
\hline Toothache/mouth pain & 12913 & 81.8 \\
Decayed tooth & 931 & 5.9 \\
Fractured teeth & 410 & 2.6 \\
Mobile teeth (periodontitis) & 379 & 2.4 \\
Jaw swelling & 252 & 1.6 \\
Replacement for missing teeth & 237 & 1.5 \\
Malocclusion & 189 & 1.2 \\
Routine check-up & 47 & 0.3 \\
Bleeding/swollen gum & 63 & 0.4 \\
Scaling and polishing & 79 & 0.5 \\
Mouth odour & 63 & 0.4 \\
Other (sensitive \& discoloured teeth) & 221 & 1.4 \\
Total & 15786 & 100.0
\end{tabular}

Table 3. Tobacco use related history of study subjects seen at the oral diagnosis unit of the Lagos State University Teaching Hospital, Nigeria 2017-2018 ( $\mathrm{N}=15786)$

\begin{tabular}{llr|r} 
& & n & $\%$ \\
\hline Tobacco use history & Yes & 4104 & 26.0 \\
documented (n=15786) & No & 11682 & 74.0 \\
History of past or current & Yes & 656 & 16.0 \\
tobacco use (n=4104) & No & 3448 & 84.0 \\
Tobacco use based on & Male & 611 & 93.1 \\
gender (n=656) & Female & 45 & 6.9 \\
Smoking cessation & Yes & 120 & 18.3 \\
assistance offered (n=656) & No & 536 & 81.7
\end{tabular}

Table 4. Results of logistic regression for odds of screening for tobacco use among patients seen at the oral diagnosis unit of the Lagos State University Teaching Hospital, Nigeria 2017-2018

\begin{tabular}{|l|c|c|c|c|}
\hline Complaint & $\begin{array}{c}\text { Proportion } \\
\text { screened } \\
\text { for tobacco } \\
\text { use }\end{array}$ & OR & $95 \%$ CI & p \\
\hline $\begin{array}{l}\text { No oral ulcers } \\
\text { Oral ulcers }\end{array}$ & $85 / 150$ & 1.94 & $1.26-2.84$ & $0.001^{*}$ \\
Continued
\end{tabular}


Table 4. Continued

\begin{tabular}{|c|c|c|c|c|}
\hline Complaint & $\begin{array}{c}\text { Proportion } \\
\text { screened } \\
\text { for tobacco } \\
\text { use }^{\mathrm{a}}\end{array}$ & OR & $95 \%$ CI & $\mathbf{p}$ \\
\hline No jaw tumors & & 1 & & \\
\hline Jaw tumors & $208 / 252$ & 2.45 & $1.67-4.38$ & $0.000^{*}$ \\
\hline Healthy periodontium & & 1 & & \\
\hline Periodontitis & $195 / 379$ & 1.43 & $0.89-2.04$ & $0.006^{*}$ \\
\hline No mouth odour & & 1 & & \\
\hline Mouth odour & $32 / 63$ & 1.38 & $1.05-1.83$ & $0.008^{*}$ \\
\hline \multicolumn{5}{|l|}{ No toothache } \\
\hline Tooth ache & $3584 / 12913$ & 0.97 & $0.59-1.22$ & 0.283 \\
\hline
\end{tabular}

\section{DISCUSSION}

Tobacco use has detrimental effects on health, including the occurrence of cardiovascular and respiratory diseases, carcinomas, and a range of other chronic ailments. Each year, tobacco use is responsible for approximately 8 million deaths worldwide, including 7 million deaths among persons who use tobacco and 1.2 million deaths among nonsmokers exposed to secondhand smoke (SHS) ${ }^{19}$. In addition to being associated with a number of cancers and coronary conditions, tobacco plays a role in the etiology of a number of oral conditions; tobacco exposes the oral cavity to toxic carcinogens that have a role in initiation and promotion of cancer $^{20}$ as well as leukoplakia, periodontitis, and delayed wound healing ${ }^{21}$. The dental practice setting thus provides a unique opportunity to assist tobacco users in achieving tobacco abstinence ${ }^{17}$. However, dental care settings remain an untapped venue for the treatment of tobacco dependence ${ }^{22,23}$.

Almost 16000 new patients were seen over 2 years in the dental clinic presenting an enormous opportunity to the dental professionals to enquire about tobacco use and initiate cessation services for those who want them. The highest proportions were young adults and the middle aged, who represent the age group that indulge most in tobacco smoking in Nigeria based on the recent WHO global report on trends in prevalence of tobacco smoking ${ }^{24}$. A significant benefit and higher tobacco abstinence rates have been observed in dental practices that focus on adult patients, who particularly appear to be responsive to the effect of interventions in this setting ${ }^{14}$. It is pertinent to note that majority of these patients attended the clinic due to some form of pain or other, while a routine preventive dental visit $(0.3 \%)$ was the least prevalent reason for a dental visit. There was no patient that presented to the clinic with a need for tobacco cessation as a presenting complaint. With over 8 million deaths attributable to smoking each year ${ }^{25}$, smoking has been described as a major public health scourge of modern times. Most tobacco users are unaware of the harm tobacco use causes ${ }^{26}$. Smoking harms almost every organ of the body and diminishes a person's overall health, and the medical side-effects of smoking have been reported in a large number of studies ${ }^{27,28}$. Various interventions have been described to combat the menace of smoking, but one that has not been sufficiently utilized is the role of health workers in smoking cessation. Folsom et al. ${ }^{29}$ reported a $2 \%$ net cessation for smokers who were advised to quit smoking by their physician compared to those who did not receive any such advice. A Cochrane review has shown that brief simple advice from the doctor about quitting smoking increases the likelihood that a smoker will quit and remain a non-smoker for 12 months after ${ }^{30}$.

The dental records that we reviewed showed that tobacco use related history was obtained from only 4104 patients representing only $26 \%$ of the patients who visited the clinic during the period under review. Of these, 656 or $16 \%$ indicated past or current tobacco use, mirroring the prevalence rates in the country ${ }^{24}$. Similar unsatisfactory rates were obtained by other researchers ${ }^{31}$. Nigerian physicians observed poor documentation of tobacco use and that many opportunities for brief intervention activities were missed. Tomar ${ }^{32}$ similarly found that $>40 \%$ of dentists do not routinely ask about tobacco use and $60 \%$ do not routinely advise tobacco users to quit. Another survey of general dentists by Albert et al. ${ }^{33}$ found that $28 \%$ of the respondents reported asking their patients about tobacco use. Approximately one half of the dentists reported advising tobacco-using patients to quit about $41 \%$ of the time. In a study of smokers who had visited a dentist within the past year, less than a fourth reported that they had been advised to quit smoking ${ }^{34}$. Widespread acceptance of tobacco use interventions in the dental setting have been lacking and limitations in primary care resources have curtailed further efforts ${ }^{16}$. Compared to other healthcare providers, dentists can assess more accurately the effects of tobacco use. However, dental practitioners have been less consistent and supportive of intervention, and are less likely to report having strong knowledge or skill levels regarding tobacco cessation, and are more likely to perceive barriers to tobacco intervention ${ }^{35}$.

Only $120(18.3 \%)$ of the patients in our review were routinely offered cessation assistance. Currently, most tobacco cessation interventions are provided by physicians, even though all healthcare providers can be equally effective ${ }^{36}$. Edwards et al. ${ }^{37}$ surveyed Australian dentists and dental hygienists and found that these practitioners indicated high rates of advising patients to quit smoking, but low rates of assisting and referring patients to smoking-cessation experts. A national survey in the US also showed that $<50 \%{ }^{38}$ of US dentists, and only a quarter of dental hygienists enquire about their patients smoking history. Fewer than 20\% of dentists had an office-based smoker identification system 
and $<5 \%$ offered follow-up services to help patients quit ${ }^{38}$. In another study that compared the quality and quantity of tobacco cessation services provided by healthcare providers, such as physicians, dentists, mental health counselors, and social workers, the authors observed that cessation interventions by dental providers ranked lowest in terms of both quantity and quality ${ }^{39}$.

In our study, patients presenting with oral ulcers and jaw tumors were significantly more likely to be screened for tobacco use compared to those with other dental complaints. Research shows that dentists whose practices emphasize the surgical aspects of dentistry where smoking can negatively affect their therapeutic outcomes tend to emphasize smoking cessation compared to those whose specialties do not ${ }^{40,41}$. A survey of oral and maxillofacial surgeons conducted by Crews et al. ${ }^{42}$ revealed that $90 \%$ of respondents reported asking about their patients' tobacco use history and that $63 \%$ advised tobacco users to quit, even though a lower proportion of them assisted with cessation and arranged for follow-up. Kunzel et al. ${ }^{43}$ found a similar pattern among general dentists.

A study done by Wyne et al. ${ }^{36}$ revealed confusion in the dental community regarding the extent of the dentist's responsibility and role in tobacco intervention. Only a minority thought of tobacco intervention as their responsibility to a 'great extent'. Several other studies in other countries have also found similar results and reported dentists were uncertain of their role in smoking cessation, and believed that it was not part of dentistry ${ }^{42,32}$. Furthermore, dentists often cite a lack of reimbursement, time constraints, and perceived patient resistance as barriers to adopting cessation treatment guidelines ${ }^{43,44}$. In the few studies that analyzed factors that may influence dentists' adherence to tobacco use treatment guidelines, a lack of training and a lack of confidence in their ability to help patients quit smoking are consistently associated with low rates of cessation intervention delivery ${ }^{43,44}$. Moreover, Albert et al. ${ }^{33}$ noted the limitation and non-systematization of courses on smoking cessation in dental schools, and efforts too often directed to the consequences of smoking. Dentists should thus be trained in smoking cessation counseling to provide smoking cessation programs in the community since they can obtain good success rates, comparable to that reported in general medical practice settings ${ }^{45}$.

\section{Strengths and limitations}

A major limitation of our study is its retrospective design. The data reported in this study were based on hospital clinical records rather than through a prospective design where the views of the dentists were sought. This study, however, has significant implications for tobacco cessation efforts in a dental setting. It also provides an initial template for further exploratory studies. Furthermore, it provides vital data for policy makers to motivate dentists to be involved in efforts to reduce the prevalence of tobacco use.

\section{CONCLUSIONS}

Our results show that $<0.01 \%$ of new patients were provided with tobacco use cessation advice, and opportunities for screening were essentially unexploited by the dental practitioners. This implies an urgent need to incorporate tobacco cessation interventions as part of standard clerking sheets that dentists utilize to screen all patients.

\section{REFERENCES}

1. The United States Food and Drug Administration. Chemicals in Cigarettes: From Plant to Product to Puff. https://www.fda. gov/tobacco-products/products-ingredients-components/ chemicals-cigarettes-plant-product-puff. Updated June 3, 2020. Accessed November 4, 2019.

2. World Health Organization. Tobacco Fact Sheet. https:// www.who.int/en/news-room/fact-sheets/detail/tobacco. Updated May 27, 2020. Accessed June 21, 2019.

3. American Cancer Society. The Tobacco Atlas: Nigeria. https:// tobaccoatlas.org/country/nigeria/. Accessed October 3, 2020.

4. Oyapero A, Oyapero O, Akinleye AI. Burden of tobacco, kola nut and alcohol consumption and its association with periodontal disease, potentially malignant lesions and quality of life among bus drivers, Lagos State, Nigeria. Popul Med. 2020;2(March):1-9. doi:10.18332/popmed/118726

5. World Health Organization. WHO report on the global tobacco epidemic, 2015: Raising taxes on tobacco. http://apps.who. int/iris/bitstream/10665/178574/1/9789240694606_eng. pdf?ua=1\&ua=1. Published 2015. Accessed June 21, 2019.

6. Drope J, Schluger N, Cahn Z, et al. The Tobacco Atlas. 6th ed. Atlanta, GA: American Cancer Society and Vital Strategies; 2018. https://tobaccoatlas.org/wp-content/ uploads/2018/03/TobaccoAtlas_6thEdition_LoRes_Rev0318. pdf. Accessed December 22, 2020.

7. Raja M, Saha S, Krishna-Reddy V, Mohd S, Narang R, Sood P. Effectiveness of oral health education versus nicotine replacement therapy for tobacco cessation- a parallel randomized clinical trial. J Clin Exp Dent. 2016;8(1):e64-e70. doi:10.4317/jced.52738

8. GBD 2015 Risk Factors Collaborators. Global, regional, and national comparative risk assessment of 79 behavioural, environmental and occupational, and metabolic risks or clusters of risks, 1990-2015: a systematic analysis for the Global Burden of Disease Study 2015. Lancet. 2016;388(10053):1659-1724. doi:10.1016/S0140-6736(16)31679-8

9. GBD 2013 Risk Factors Collaborators. Global, regional, and national comparative risk assessment of 79 behavioural, environmental and occupational, and metabolic risks or clusters of risks in 188 countries, 1990-2013: a systematic analysis for the Global Burden of Disease Study 2013. Lancet. 2015;380(10010):2287-2323.

10. Heydari G, Ebn Ahmady A, Lando HA, Shadmehr MB, Fadaizadeh L. The second study on WHO MPOWER tobacco control scores in Eastern Mediterranean Countries based on the 2013 report: improvements over two years. Arch Iran 
Med. 2014;17(9):621-625. PMID:25204478.

11.Jha P. The hazards of smoking and the benefits of cessation: a critical summation of the epidemiological evidence in high-income countries. Elife. 2020;9:e49979. doi:10.7554/eLife.49979

12. Shangase ZP, Tsoka-Gwegweni JM, Egbe CO. Barriers to Smoking Cessation Among Drug-Resistant Tuberculosis Patients in South Africa. Ann Glob Health. 2017;83(3-4):501508. doi:10.1016/j.aogh.2017.05.007

13. Selby P, Hunter K, Rogers J, et al. How to adapt existing evidence-based clinical practice guidelines: a case example with smoking cessation guidelines in Canada. BMJ Open. 2017;7(11):e016124. doi:10.1136/bmjopen-2017-016124

14. Stead LF, Buitrago D, Preciado N, Sanchez G, HartmannBoyce J, Lancaster T. Physician advice for smoking cessation. Cochrane Database Syst Rev. 2013;2013(5):CD000165. doi:10.1002/14651858.CD000165.pub4

15. American Dental Association. Summary of Policy and Recommendations Regarding Tobacco: 1964 - Present. https://www.ada.org/en/advocacy/current-policies/copyof-tobacco-use. Accessed September 11, 2019.

16. Carr AB, Ebbert J. Interventions for tobacco cessation in the dental setting. Cochrane Database Syst Rev. 2012;2012(6):CD005084. doi:10.1002/14651858.CD005084.pub3

17. Alajmi B, Abu-Hammad O, Al-Sharrad A, Dar-Odeh N. Tobacco cessation support among dentists: A cross-sectional survey in Saudi Arabia and Kuwait. Tob Prev Cessation. 2017;3(August):1-8. doi:10.18332/tpc/75795

18. Bakare TI, Okoturo E, Obisesan B, Oyapero A. Patients' attitudes toward screening for medical conditions in a dental clinic at the Lagos State University Teaching Hospital, Ikeja. International Journal of Health \& Allied Sciences. 2018;7(3):150-158. doi:10.4103/ijhas.IJHAS_110_17

19. GBD 2017 Risk Factor Collaborators. Global, regional, and national comparative risk assessment of 84 behavioural, environmental and occupational, and metabolic risks or clusters of risks for 195 countries and territories, 1990-2017: a systematic analysis for the Global Burden of Disease Study 2017. Lancet. 2018;392(10159):1923-1994. doi:10.1016/S0140-6736(18)32225-6

20. Ebersole J, Samburova V, Son Y, et al. Harmful chemicals emitted from electronic cigarettes and potential deleterious effects in the oral cavity. Tob Induc Dis. 2020;18(May):1-16. doi: $10.18332 /$ tid/116988

21. Pontes CC, Chikte U, Kimmie-Dhansay F, Erasmus RT, Kengne AP, Matsha TE. Prevalence of Oral Mucosal Lesions and Relation to Serum Cotinine Levels-Findings from a CrossSectional Study in South Africa. Int J Environ Res Public Health. 2020;17(3):1065. doi:10.3390/ijerph17031065

22. Goel D, Patthi B, Singla A, Malhi R, Chaudhary PK, Khan A. Assessment of knowledge and attitude regarding management of patients with substance usage in dental clinics in Modinagar- A cross-sectional study. J Family Med Prim Care. 2019;8(11):3683-3688. doi:10.4103/jfmpc.jfmpc_733_19

23.Fleming E, Singhal A. Chronic Disease Counseling and Screening by Dental Professionals: Results From NHANES, 2011-2016. Prev Chronic Dis. 2020;17:E87. doi:10.5888/pcd17.200152

24. World Health Organization. WHO global report on trends in prevalence of tobacco smoking 2015. https://apps.who.int/ iris/bitstream/handle/10665/156262/9789241564922_ eng.pdf;jsessionid=6D7FA697CEA010730E7A09547550 E303?sequence=1. Published 2015. Accessed June 11, 2020.

25. World Health Organization. WHO report on the global tobacco epidemic 2019: offer help to quit tobacco use. https://www.who.int/publications/i/item/9789241516204. Published July 25, 2019. Accessed December 21, 2020.

26. Veeraiah S, Elangovan V, Tripathy JP, et al. Quit attempts among tobacco users identified in the Tamil Nadu Tobacco Survey of 2015/2016: a 3 year follow-up mixed methods study. BMJ Open. 2020;10(9):e034607. doi:10.1136/bmjopen-2019-034607

27. Castillo-Riquelme M, Bardach A, Palacios A, Pichón-Riviere A. Health burden and economic costs of smoking in Chile: The potential impact of increasing cigarettes prices. PLoS One. 2020;15(8):e0237967. doi:10.1371/journal.pone.0237967

28. Oshunbade AA, Yimer WK, Valle KA, et al. Cigarette Smoking and Incident Stroke in Blacks of the Jackson Heart Study. J Am Heart Assoc. 2020;9(12):e014990. doi:10.1161/JAHA.119.014990

29. Folsom AR, Grimm RHJ. Stop smoking advice by physicians: a feasible approach?. Am J Public Health. 1987;77(7):849-850. doi:10.2105/ajph.77.7.849

30. Lancaster T, Stead L. Physician advice for smoking cessation. Cochrane Database Syst Rev. 2004;(4):CD000165. doi:10.1002/14651858.CD000165.pub2

31. Odukoya O, Jamda M, Onigbogi O, et al. Tobacco Cessation Interventions in Tertiary Hospitals in Nigeria: An Audit of Patient Records. Nicotine Tob Res. 2017;19(8):983-989. doi:10.1093/ntr/ntw397

32. Tomar SL. Dentistry's role in tobacco control. J Am Dent Assoc. 2001;132(Suppl 1):30S-35S. doi:10.14219/jada.archive.2001.0386

33. Albert DA, Severson H, Gordon J, Ward A, Andrews J, Sadowsky D. Tobacco attitudes, practices, and behaviors: a survey of dentists participating in managed care. Nicotine Tob Res. 2005;7(Suppl 1):S9-S18. doi:10.1080/14622200500078014

34. Tomar SL, Husten CG, Manley MW. Do dentists and physicians advise tobacco users to quit? J Am Dent Assoc. 1996;127(2):259-265. doi:10.14219/jada.archive.1996.0179

35. Block DE, Block LE, Hutton SJ, Johnson KM. Tobacco counseling practices of dentists compared to other health care providers in a midwestern region. J Dent Educ. 1999;63(11):821-827. do i:10.1002/j.0022-0337.1999.63.11.tb03318.x

36. La Torre G, Tiberio G, Sindoni A, Dorelli B, Cammalleri V. Smoking cessation interventions on health-care workers: a systematic review and meta-analysis. PeerJ. 2020;8:e9396. doi:10.7717/peerj.9396

37. Edwards D, Freeman T, Roche AM. Dentists' and dental hygienists' role in smoking cessation: an examination and 
comparison of current practice and barriers to service provision. Health Promot J Austr. 2006;17(2):145-151. doi:10.1071/he06145

38. Barker G], Williams KB. Tobacco use cessation activities in U.S. dental and dental hygiene student clinics. J Dent Educ. 1999;63(11):828833. doi:10.1002/J.0022-0337.1999.63.11.TB03319.X

39. Secker-Walker RH, Solomon LJ, Flynn BS, Dana GS. Comparisons of the smoking cessation counseling activities of six types of health professionals. Prev Med. 1994;23(6):800-808. doi:10.1006/pmed.1994.1137

40. Crews KM, Sheffer CE, Payne TJ, Applegate BW, Martin A, Sutton T. A survey of oral and maxillofacial surgeons' tobacco-use-related knowledge, attitudes and intervention behaviors. J Am Dent Assoc. 2008;139(12):1643-1651. doi:10.14219/jada.archive.2008.0106

41. Kunzel C, Lalla E, Albert DA, Yin H, Lamster IB. On the primary care frontlines: the role of the general practitioner in smoking-cessation activities and diabetes management. J Am Dent Assoc. 2005;136(8):1144-1167. doi:10.14219/jada.archive.2005.0320

42. Brothwell DJ, Armstrong KA. Smoking cessation services provided by dental professionals in a rural Ontario health unit. J Can Dent Assoc. 2004;70(2):94-98. PMID:14756939.

43. Prakash P, Belek MG, Grimes B, et al. Dentists' attitudes, behaviors, and barriers related to tobacco-use cessation in the dental setting. J Public Health Dent. 2013;73(2):94-102. doi:10.1111/j.1752-7325.2012.00347.x

44. McNeely J, Wright S, Matthews AG, et al. Substance-use screening and interventions in dental practices: survey of practice-based research network dentists regarding current practices, policies and barriers. J Am Dent Assoc. 2013;144(6):627-638. doi:10.14219/jada.archive.2013.0174

45. Wood GJ, Cecchini JJ, Nathason N, Hiroshige K. Office-based training in tobacco cessation for dental professionals. J Am Dent Assoc. 1997;128(2):216-224. doi:10.14219/jada.archive.1997.0168

CONFLICTS OF INTEREST

The authors have completed and submitted the ICMJE Form for Disclosure of Potential Conflicts of Interest and none was reported.
PROVENANCE AND PEER REVIEW

Not commissioned; externally peer reviewed.

FUNDING

There was no source of funding for this research. 